\title{
PROPOSTA METODOLÓGICA PARA MAPEAMENTO DE RISCO DE INUNDAÇÃO NO MUNICÍPIO DE CURITIBA (PARANÁ)
}

\author{
Renato Eugênio de Lima \\ Universidade Federal do Paraná (UFPR) \\ Departamento de Geologia, Curitiba, PR, Brasil \\ renatolima@ufpr.br \\ Luis Alberto Lopez Miguez \\ Secretaria Municipal do Meio Ambiente de Curitiba, Curitiba, PR, Brasil \\ Imiguez@smma.curitiba.pr.gov.br \\ Fabiane Aline Acordes \\ Coordenadoria Estadual de Proteção e Defesa Civil do Paraná, Curitiba, PR, Brasil \\ fabiane.acordes@gmail.com \\ Murilo Noli da Fonseca \\ Pontifícia Universidade Católica do Paraná (PUCPR) \\ Programa de Pós-Graduação em Gestão Urbana, Curitiba, PR, Brasil \\ murilonoli@gmail.com
}

\begin{abstract}
RESUMO
As inundações são um dos fenômenos naturais que geram impactos em um maior número de pessoas no mundo. Dentre as medidas necessárias para o enfrentamento deste processo perigoso, o mapeamento de áreas de risco possibilita identificar as áreas que podem ser atingidas e o potencial prejuízo no caso de sua ocorrência. É uma ação básica de custo relativamente moderado ou baixo e de alta eficácia. Portanto, o presente trabalho tem como objetivo propor e aplicar uma nova metodologia para mapeamento de áreas de risco a inundações no município de Curitiba, capital do Estado do Paraná. A mensuração de risco compreende a análise da vulnerabilidade e do perigo, considerando aspectos do meio físico (geologia, declividade, histórico de inundações) e socioeconômico (equipamentos essenciais, potencial poluidor e vulnerabilidade social). Tais fatores foram processados a partir do software Vista S.A.G.A. 2007, da Universidade Federal do Rio de Janeiro. Determinaram-se, assim, os setores que possuem maior risco a inundações e que devem ser alvos de políticas públicas e medidas mitigadoras.
\end{abstract}

Palavras-chave: Gestão de risco. Cartografia. Prevenção. Redução de risco de desastre.

\section{METHODOLOGICAL PROPOSAL FOR FLOOD RISK MAPPING IN THE CITY OF CURITIBA (PARANÁ)}

\begin{abstract}
Floods are one of the natural phenomena that generate impacts on a greater number of people in the world. Among the measures necessary to cope with this dangerous process, the mapping of risk areas makes it possible to identify the areas that can be affected and the potential damage in the event of its occurrence. It is a basic action of relatively moderate or low cost and high effectiveness. Therefore, the present work aims to propose and apply a new methodology for mapping flood risk areas in the municipality of Curitiba, capital of the State of Paraná. Risk measurement includes the analysis of vulnerability and danger, considering aspects of the physical (geology, slope, history of floods) and socioeconomic (essential equipment, polluting potential and social vulnerability). These factors were processed from the Vista S.A.G.A. 2007 software from the Federal University of Rio de Janeiro. Thus, the sectors that are most at risk to floods and that should be targets of public policies and mitigating measures were determined.
\end{abstract}

Keywords: Risk management. Cartography. Prevention. Disaster risk reduction.

\section{INTRODUÇÃO}

Desde os primórdios da humanidade, o ser humano tem se confrontado com os riscos na sua relação com a natureza. Ao abrigarem-se em um determinado local, com a finalidade de aproveitar seus recursos e a sua disposição, os indivíduos passam a relacionar-se com os fenômenos naturais que poderão ameaçá-lo.

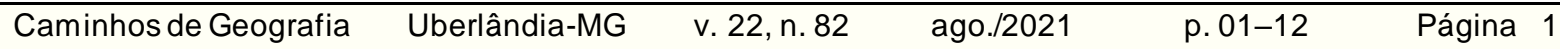


Entretanto, tal situação auf ere proeminência à medida que o século $X X$ marca a eclosão das condições de riscos em que a sociedade hodierna se encontra exposta, sobretudo aquela que reside em áreas urbanas. Entre 2005 e 2014, por exemplo, ocorreram 335 desastres deflagrados por eventos de origem natural no planeta, representando 14\% de acréscimo em relação ao período compreendido entre 1995 e 2004 e cerca do dobro de 1985-1995, onde 90\% do seventos tiveram origem climatológica. Ainda, o Escritório das Nações Unidas para a Redução de Desastres (UNISDR) estipula que os prejuízos decorrentes desses eventos no planeta totalizam cerca de 300 bilhões de dólares/ano. O período 1995-2015 registrou um dos maiores números de pessoas afetadas no mundo, atingindo 51 milhões de pessoas (ONUBR, 2015).

Embora não seja possível diminuir o crescimento do número de ocorrências relacionadas a tais fenômenos, podem ser desenvolvidas medidas preventivas que possibilitam mitigar os impactos desses eventos sobre o território e a sociedade. Entre tais medidas, distinguem-se as estruturais e as não-estruturais. A primeira é caracterizada pela implantação de obras de engenharia, como a construção de diques, barragens, piscinões, entre outros. Já as não-estruturais se destacam pelo seu baixo custo de implementação e envolvem a implantação de políticas públicas, dados abertos (FONSECA, FERENTZ e GARCIAS, 2020), comunicação de risco (FONSECA e GARCIAS, 2020), mapeamento de áreas de risco, capacitação (PINHEIRO, FERENTZ e FONSECA, 2019) e educação ambiental, entre outros.

A Lei Federal no 12.608, de 10 de abril de 2012, que institui a Política Nacional de Proteção e Def esa Civil (PNPDEC), traz um forte apelo às ações de prevenção aos desastres deflagrados por eventos naturais a partir de medidas estruturantes, destacando-se entre elas o mapeamento de áreas de risco (BRASIL, 2012). Nesse contexto, na sua evolução urbana, o município de Curitiba (Paraná) sucessivamente se deparou com problemas atrelados às inundações. Mas foi a partir da criação do Setor de Gestão de Riscos, em 2013, no âmbito da Secretaria Municipal de Meio Ambiente, que foram realizados os primeiros mapeamentos de risco relacionados à inundação, sobretudo nas bacias dos Rios Ponta Grossa e Atuba.

Baseado nessa circunstância, o presente trabalho tem como objetivo apresentar uma proposta metodológica para mapeamento de áreas de risco de inundação para toda a capital paranaense.

\section{CONCEITO DE PERIGO E VULNERABILIDADE PARA O MAPEAMENTO DE ÁREAS DE RISCO}

As repercussões geradas por eventos adversos e desastres no espaço geográfico e sobre as atividades humanas têm recebido cada vez mais atenção dos gestores públicos, do meio acadêmico e da sociedade. Tais eventos ocorrem com maior frequência e intensidade em ambientes urbanos, já que nessas áreas ocorre uma das maiores transformações do espaço natural, e tendem a extrapolar a capacidade de absorção de seus ef eitos pela sociedade, que se encontra planejada e organizada com base nos estados médios dos sistemas atmosféricos, ignorando seu ritmo e a sua variabilidade natural (MONTEIRO, 1991).

Nesse contexto, inúmeros autores inserem o conceito de perigo (hazard) e o definem como sendo eventos que interrompem um ciclo ou um ritmo de ocorrência de repercussões geográficas de natureza climática e meteorológica (MARANDOLA JR. e HOGAN, 2004). Ressalta-se que nem todos os eventos devem ser considerados como perigosos, mas exclusivamente aqueles "que estão em relação ou ocorrendo em áreas ocupadas pelo homem, gerando danos, perdas e colocando em perigo estas populações" (MARANDOLA JR. e HOGAN, 2004, p. 98). Rigorosamente falando, os eventos e processos naturais que não interagem com a sociedade não são perigosos, são apenas eventos naturais, que causam a ruptura de um ritmo e ocorrem em uma determinada área do espaço.

Os impactos negativos de um evento adverso sobre a sociedade assinalam um desastre. Isso não é novo, uma vez que acontece desde a constituição das primeiras aglomerações humanas até a concepção contemporânea das cidades (MONTEIRO, 1991). Os desastres são o resultado da ocorrência de grandes eventos adversos, sejam eles naturais ou provocados pelo homem, sobre um cenário vulnerável (BRASIL, 2012), acarretando em danos humanos, ambientais e/ou materiais e prejuízos ao patrimônio público e privado de grande monta (muitas mortes ou grande destruição). Portanto, a ocorrência de um desastre sempre está associada às perdas, sejam elas econômicas, sociais ou ambientais. De forma que o termo risco pode ser interpretado como a probabilidade de consequências adversas ou perdas resultantes da interação entre perigos e os sistemas humanos (UNDP, 2004). Outra forma usual de definição de risco refere-se a seguinte função: $R=f(H, V)$, onde $R$ é risco, H é perigo (hazard), e V é vulnerabilidade.

Em relação à vulnerabilidade, não há um consenso sobre o conceito, já que vem sendo empregado em múltiplos campos disciplinares, resultando em inúmeras definições explicadas por seus aspectos específicos, que dependem do tipo de perigo analisado, das escalas temporal e espacial e das especificidades do local de estudo (BARROCA et al., 2006; FONSECA e FERENTZ, 2020). Ela está associada à condição dos indivíduos e/ou comunidades e pode ser mensurada a partir do grau esperado

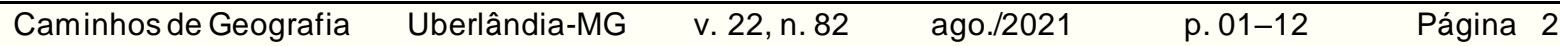


de danos e prejuízos que um evento adverso pode desencadear. No presente trabalho, a vulnerabilidade será abordada de acordo com os tipos descritos por Hill e Cutter (2001): individual, social e biofísica.

- Vulnerabilidade individual: diz respeito à suscetibilidade de uma pessoa ou uma estrutura sofrer um dano potencial. As características de uma estrutura (tipo de material, projeto) ou de uma pessoa (idade, condição de saúde, estilo de vida, alimentação) são levadas em conta para a sua determinação.

- Vulnerabilidade social: baseia-se nas características demográficas de grupos sociais, as quais os tornam mais ou menos vulneráveis. Para a sua determinação é necessário à utilização de diversas características socioeconômicas, tais como idade, renda, gênero, educação, entre outros.

- Vulnerabilidade biofísica: está diretamente relacionada à exposição física, isto é, o quanto um local/área é suscetível à ocorrência de um perigo natural.

Dentre os eventos extremos, os hidrometeóricos são os maiores respons áveis pela geração de desastres no Brasil (CEPED-UFSC, 2012). Tais eventos encontram-se atrelados a precipitações extremas e associada a características geográficas dos lugares e aos seus problemas recorrentes geram fenômenos de ordem negativa, isto é, inundações, enxurradas e alagamentos. A inundação é a situação em que o fluxo de um no ultrapassa os limites do seu leito normal, avançando sobre os terrenos localizados além de suas margens (LIMA, 2000). Esse processo é inerente à dinâmica natural do rio e varia quanto à magnitude e ao intervalo de recorrência. No entanto, devido à expansão urbana e ao aumento populacional das últimas décadas as planícies de inundação foram intensamente ocupadas.

Tais definições embasam a metodologia de mapeamento de risco de inundação proposta neste trabalho. A partir desse tipo de mapa é possível subsidiar o desenvolvimento de medidas preventivas, estabelecer protocolos de atendimento em situações de emergência e ações conjuntas entre a comunidade e o poder público, de modo a promover estratégias de prevenção contra os eventos extremos e desastres.

\section{METODOLOGIA}

\section{DESCRIÇÃO DA ÁREA DE ESTUDO}

O município de Curitiba está inserido no Primeiro Planalto Paranaense, na porção centro-sul. É limitado a oeste pela escarpa da Serra de São Luiz do Purunã, a leste pela Serra do Mar e a norte por um relevo mais íngreme, fruto de rochas metamórficas do Grupo Açungui. Localiza-se a $945 \mathrm{~m}$ de altitude, ocupando uma área de $435,495 \mathrm{~km}^{2}$, que é totalmente é urbanizada (FIGURA 1). Destaca-se como cidade polo de sua região metropolitana, a qual é composta por mais 29 municípios. Atualmente, possui população estimada de 1.908.359 habitantes, e densidade demográfica de 4.382,05 hab./km² (IPARDES, 2018).

Figura 1 - Localização de Curitiba (Paraná).

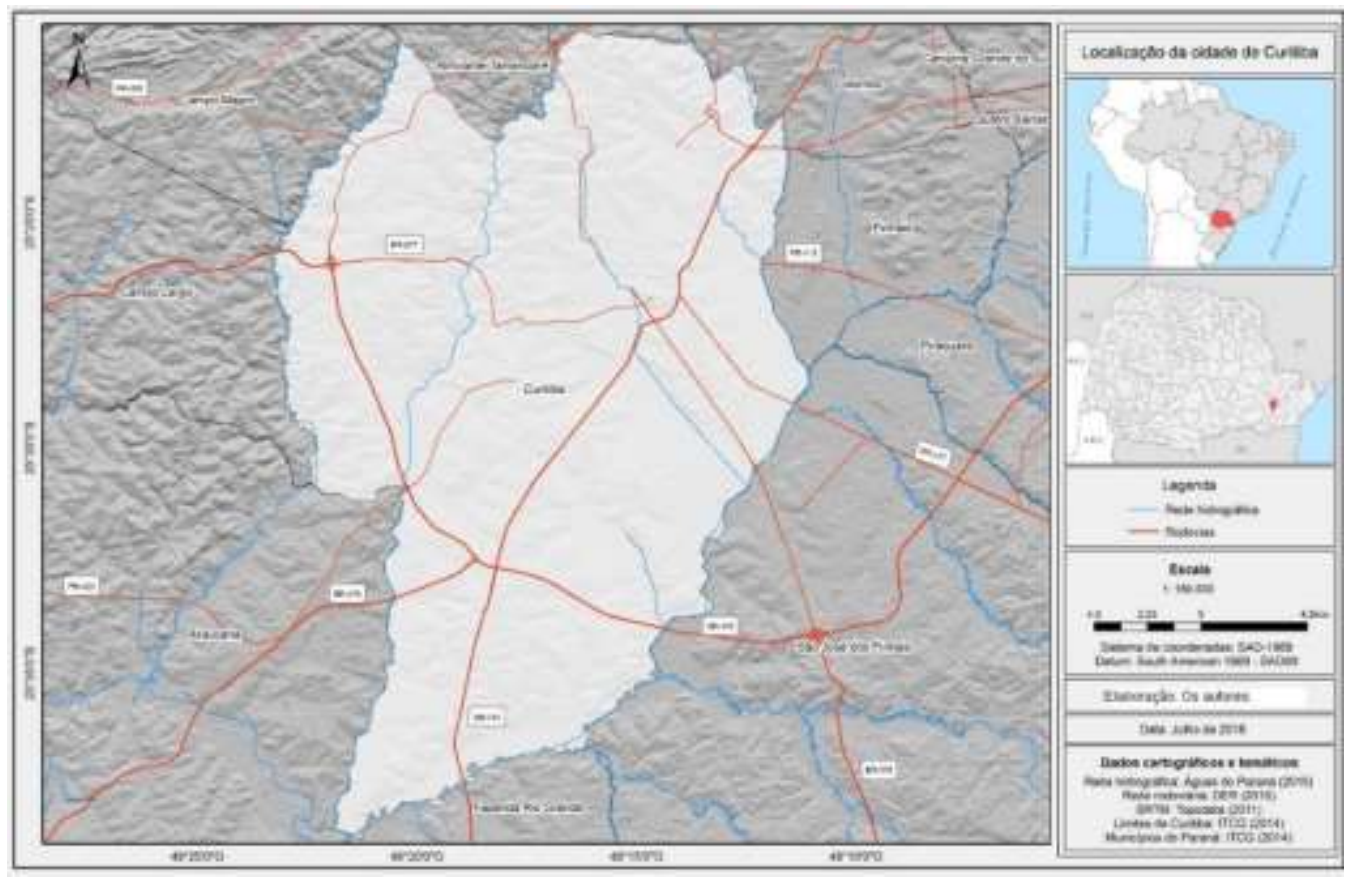

Fonte - Os autores (2020).

$\begin{array}{llllll}\text { Caminhos de Geografia } & \text { Uberlândia-MG } & \text { v. 22, n. } 82 & \text { ago./2021 } & \text { p. 01-12 } & \text { Página } 3\end{array}$


(físicos e sociais) na geração dos riscos no município, como geologia, geomorfologia, uso e ocupação do solo, histórico de inundações, aspectos sociais e infraestrutura. Após isso, os temas foram determinados e representados através de seis mapas temáticos: geologia, declividade, histórico de inundações, considerando os aspectos físicos, equipamentos essenciais, potencial poluidor e vulnerabilidade social, abarcando aspectos socioeconômicos cada qual com sua relevância.

A partir dos mapas temáticos, elaborou-se os mapas de "Favorabilidade de Processos Perigosos" (F.P.P.) e "Possibilidade de Prejuízos e Danos" (P.P.D.) (FIGURA 2), que geram o "Mapa de risco de Inundação".

Figura 2 - Sistemática aplicada para a execução do Mapa de Riscos de Inundação de Curitiba.

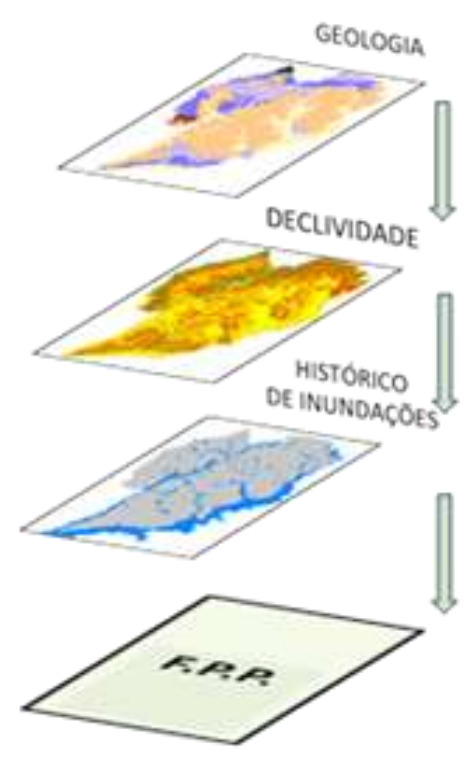

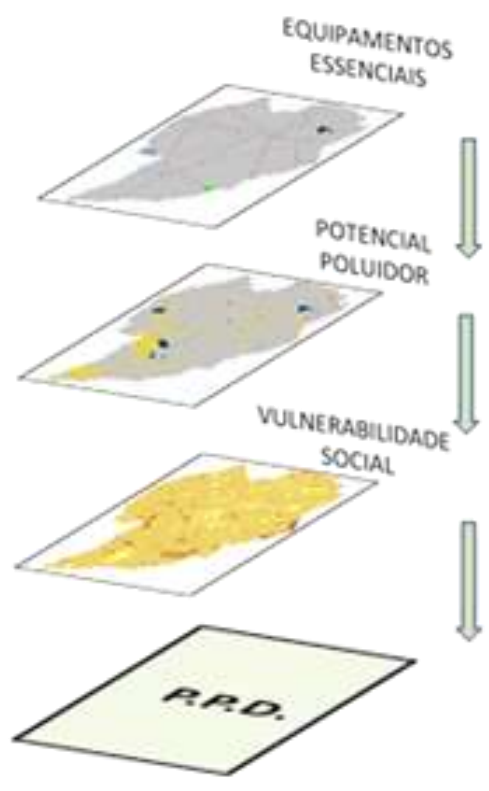

Fonte - Os autores (2020).
Note:

F.P.P. = Farora bilidade de Procassos Pe rícose.

P.P.D = Rossibilidade de Pre juivos e De nos.

F.P.P + P.P.D $=$ MAPA, DE RISCOS

\section{AVALIAÇÃO DO RISCO}

Todos os dados compilados, que compõe os mapas temáticos avaliados, encontram-se em arquivos formato shapefile e foram utilizados no programa ArcView ${ }^{\circledR} 3.2^{\mathrm{a}}$, sendo lançados sobre a base cartográfica georref erenciada de Curitiba. Cada mapa elaborado para a avaliação de risco foi exportado em formato de arquivo de imagem bitmap, para atender a exigência do programa utilizado para o processamento das informações. O programa utilizado para a execução do mapa de risco foi o Vista S.A.G.A. 2007 (Sistema de Análise Geo-Ambiental), da Universidade Federal do Rio de Janeiro (UFRJ). Este programa trabalha com arquivos tipo raster, ou seja, imagens, por isso a necessidade de todos os mapas estarem no formato bitmap. Na imagem raster, cada pixel possui um valor de cor. A partir da imagem raster original, uma imagem Raster-SAGA, cada pixel informa, além da cor, a categoria relacionada a este e as coordenadas UTM (Universal Transversal de Mercator). Nas imagens Raster-SAGA, a resolução da imagem é informada em metros, indicando quantos metros quadrados do terreno real estão representados em 1 pixel (UFRJ, 2007). No caso das imagens Raster-SAGA geradas, a resolução espacial foi de 3,84 metros.

Para que se faça o processo de avaliação do risco em ambiente Vista SAGA, deve-se atribuir pesos para cada mapa utilizado no processo (somando-se 100\%), assim como notas de importância de cada classe que compõe cada um dos mapas (de 0 a 10). Após a avaliação é gerado um arquivo raster matricial, que consiste em uma estrutura de dados celular composta por linhas e colunas para o armazenamento de imagens (UFRJ, 2007). Por fim, gerou-se o formato de arquivo Raster-SAGA/UFRJ. Tal formato, de estrutura raster, possui características singulares em relação aos demais formatos existentes. Ap resenta

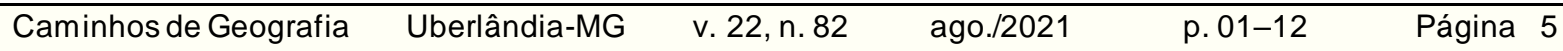


atributos como resolução espacial do mapa, informação de coordenadas UTM de cada ponto, além da informação da legenda referente a qualquer ponto deste (UFRJ, 2007).

$\mathrm{Na}$ metodologia utilizada na elaboração do Mapa de Risco Associado a Inundações de Curitiba foram atribuídos os pesos de mapas e notas de classes (FIGURA 3).

Figura 3 - Diagrama da composição do Mapa de Riscos Associados a Inundações de Curitiba. Em vermelho, os pesos atribuídos aos mapas temáticos (somam 100\% por coluna). Em verde, notas atribuídas às classescontidas nos mapas temáticos (variam de 0 a 10).

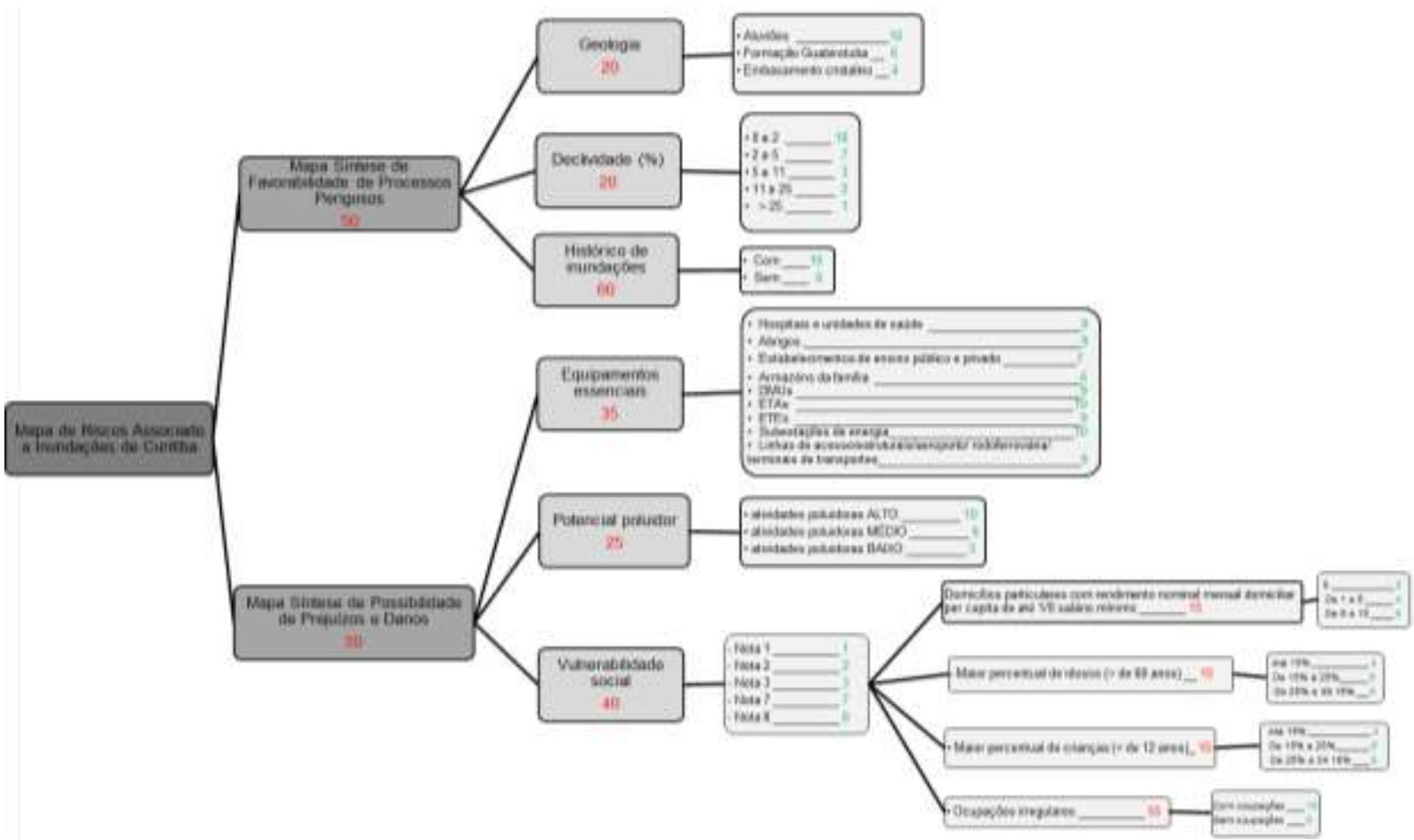

Fonte - Os autores (2020)

\section{MAPA SÍNTESE DE FAVORABILIDADE DE PROCESSOS PERIGOSOS}

Este tipo de mapa apresenta o comportamento do elemento analisado com base em características que não possuem ou que possuem pouca influência antrópica (FIGURA 4). Leva-se em consideração nomeadamente inf ormações das características morfológicas da área af etada pela inundação. Destarte, um elemento importante para compor esta análise é o mapa de histórico de inundações, que nos fornece informações de comportamento do rio ao longo dos anos, com a possibilidade de análise da influência da atividade antrópica no seu escoamento ou vazão. Outros mapas que devem ser considerados são o de geologia, que descreve o tipo de terreno e suas características, e o de declividade, onde se podem observar as áreas mais planas sujeitas à inundação. Para a elaboração do "Mapa Síntese de Favorabilidade de Processos Perigosos" foram utilizados os seguintes mapas temáticos:

a) Mapa de histórico de inundações, com a delimitação das áreas que já apresentaram ou que estão sujeitas a inundação. Tais dados foram obtidos por meio do Plano Diretor de Drenagem de Curitiba (2012). Utilizaram-se, nesta análise, os polígonos de abrangência da inundação. Foram consideradas as seguintes classes: áreas sem histórico e áreas com histórico de inundações.

b) Mapa de declividade, obtido por meio de processamento digital das curvas de nível do município (intervalo de $1 \mathrm{~m}$ ). O elemento de análise são os polígonos que representam as faces das classes de declividade. Para tal mapa, foram consideradas as seguintes classes: $0^{\circ}-2^{\circ} 2^{\circ}-5^{\circ} 5^{\circ}-11^{\circ} 11^{\circ}-25^{\circ}$ e $>25^{\circ}$.

c) Mapa de geologia, com as diferentes litologias que caracterizam a geomorfologia do terreno e o comportamento desses tipos de rochas frente aos processos de intemperismo. Para a caracterização

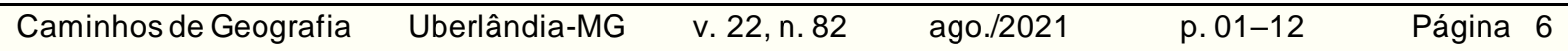


geológica, foram considerados as informações dos trabalhos de Bigarella e Salamuni (1962), Salamuni et al. (1999), Salamuni, Ebert e Hasui (2004). Para a presente análise foram utilizados polígonos das unidades litológicas. Para tanto, utilizou-se as seguintes categorias: Embasamento Cristalino Formação Guabirotuba e Aluviões.

Figura 4 - Mapa Síntese de Favorabilidade de Processos Perigosos.

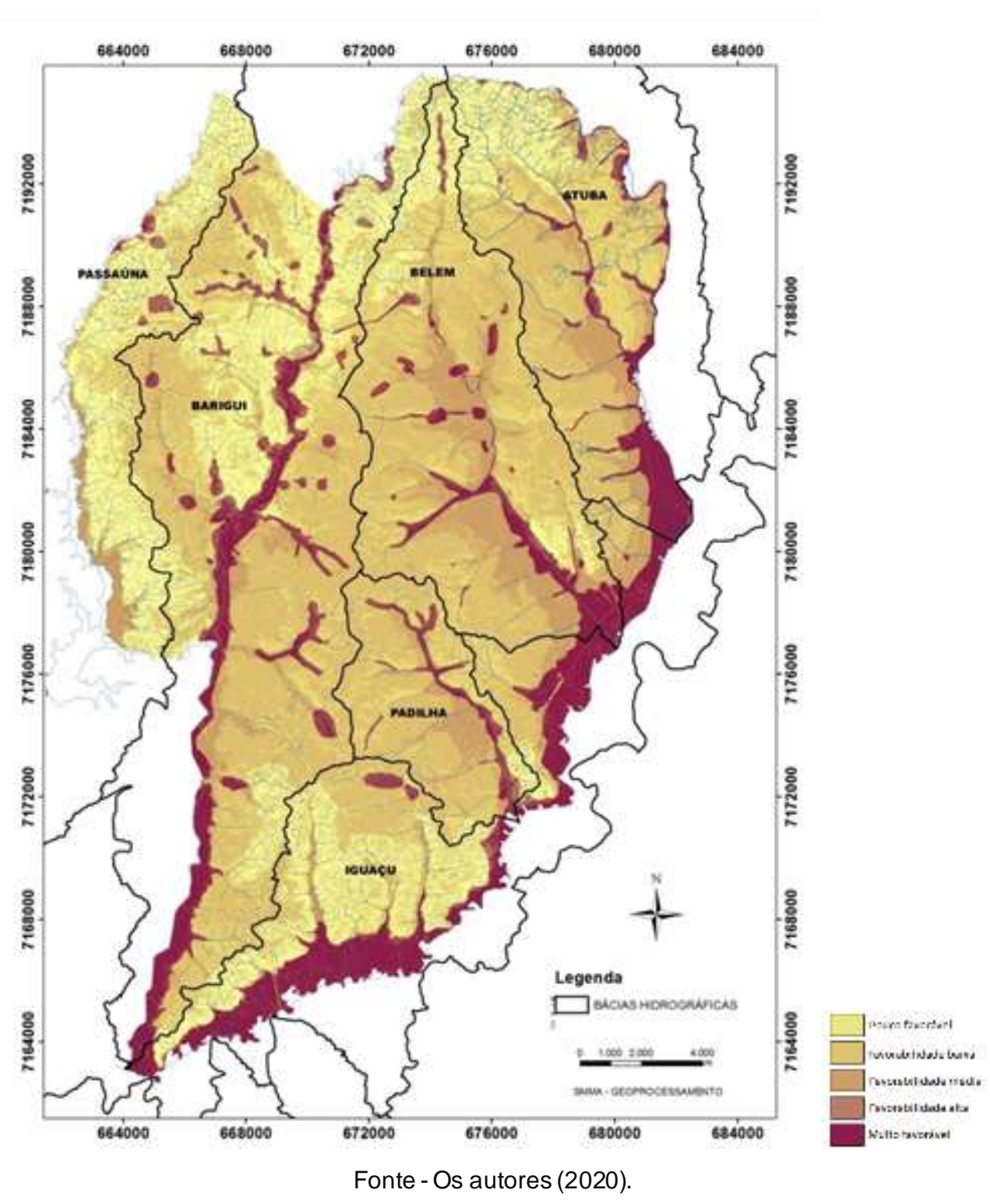

\section{MAPA SÍNTESE DE FAVORABILIDADE DE PREJUÍZOS E DANOS}

É o tipo de mapa que apresenta a possibilidade de dano aos indivíduos, bens e infraestruturas, como consequência da ocorrência de inundações (FIGURA 5). Estes elementos estão comumente associados ao processo de urbanização das cidades. Para a elaboração deste mapa foi empregada a seguinte co mpilação de mapas temáticos:

a) Mapa de equipamentos essenciais, com a marcação dos serviços essenciais à população. Consideraramse os serviços que, se atingidos por inundação, causariam maiores prejuízos à população. Os dados referentes aos abrigos para desabrigados foram fornecidos pela Coordenadoria Municipal de Proteção e Def esa Civil. Todos os outros foram obtidos através de base cartográfica oficial de cada Secretaria Municipal responsável pela informação (Secretarias de Educação, Saúde, Urbanismo, Governo Municipal,

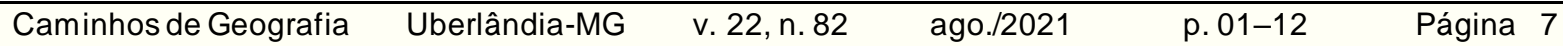


Abastecimento e Planejamento), disponibilizada pelo Instituto de Pesquisa e Planejamento Urbano de Curitiba (IPPUC). Foram considerados os seguintes serviços: hospitais e unidades de saúde abrigos estabelecimentos de ensino público e privado armazéns da família Distrito de Manutenção Urbana Estações de Tratamento de Água Estações de Tratamento de Esgoto subestações de energia e transportes (principais linhas de acesso, aeroporto, heliponto, rodoferroviária e terminais).

b) Mapa de potencial poluidor, com a marcação das atividades consideradas sensíveis, tais como cemitérios, indústrias, postos de combustível e laboratórios, no que se refere à contaminação de água/solo, quando da possibilidade de ocorrência de inundação. Para tanto, utilizou-se os lotes inseridos no município, em forma de polígonos. Cada lote foi pesquisado quanto à atividade desenvolvida, conforme cadastro no Sistema de Monitoramento Ambiental (SIMA), da Secretaria Municipal de Meio Ambiente (SMMA). As atividades foram então classificadas em níveis, de acordo com o potencial de poluição que as substâncias comumente utilizadas nesses locais oferecem à população, caso sejam ating idos por inundação: alto, médio e baixo potencial poluidor.

c) Mapa de vulnerabilidade, com as características podem fazer com que os danos, em caso de ocorrência de inundação, sejam agravados. Os dados de ocupações irregulares provêm do IPPUC. Os demais se referem ao censo realizado pelo IBGE (2010) e a unidade de análise utilizada foram os setores censitánios. Foram consideradas as seguintes classes: domicílios com renda per capita de até $1 / 8$ do salário mínimo percentual de idosos (considerados os acima de 60 anos, conforme o Estatuto do Idoso) percentual de crianças (consideradas as com até 12 anos, conforme o Estatuto da Criança e do Adolescente) e ocupações irregulares.

Figura 5 - Mapa Síntese de Favorabilidade de Prejuízose Danos.

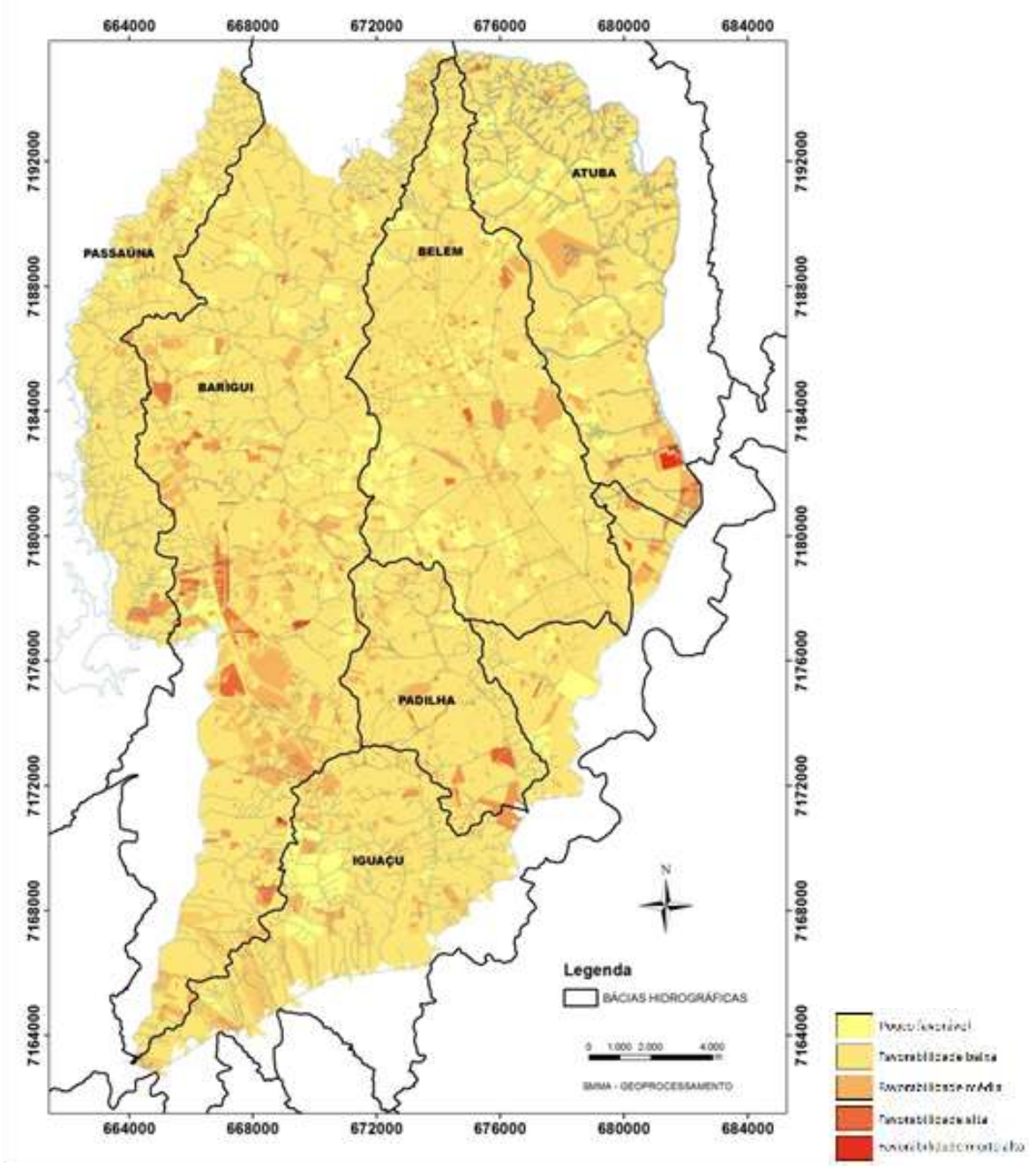

Fonte - Os autores (2020). 


\section{RESULTADOS E DISCUSSÃO}

O mapeamento de risco de inundação de Curitiba identificou cinco classes de risco por ocorrência de chuvas intensas: classe 1 - risco inexistente classe 2 - risco baixo classe 3 - risco médio classe 4 - risco alto e classe 5 - risco muito alto (FIGURA 6).

Figura 6 - Mapa de risco associado a inundações no município de Curitiba - PR.

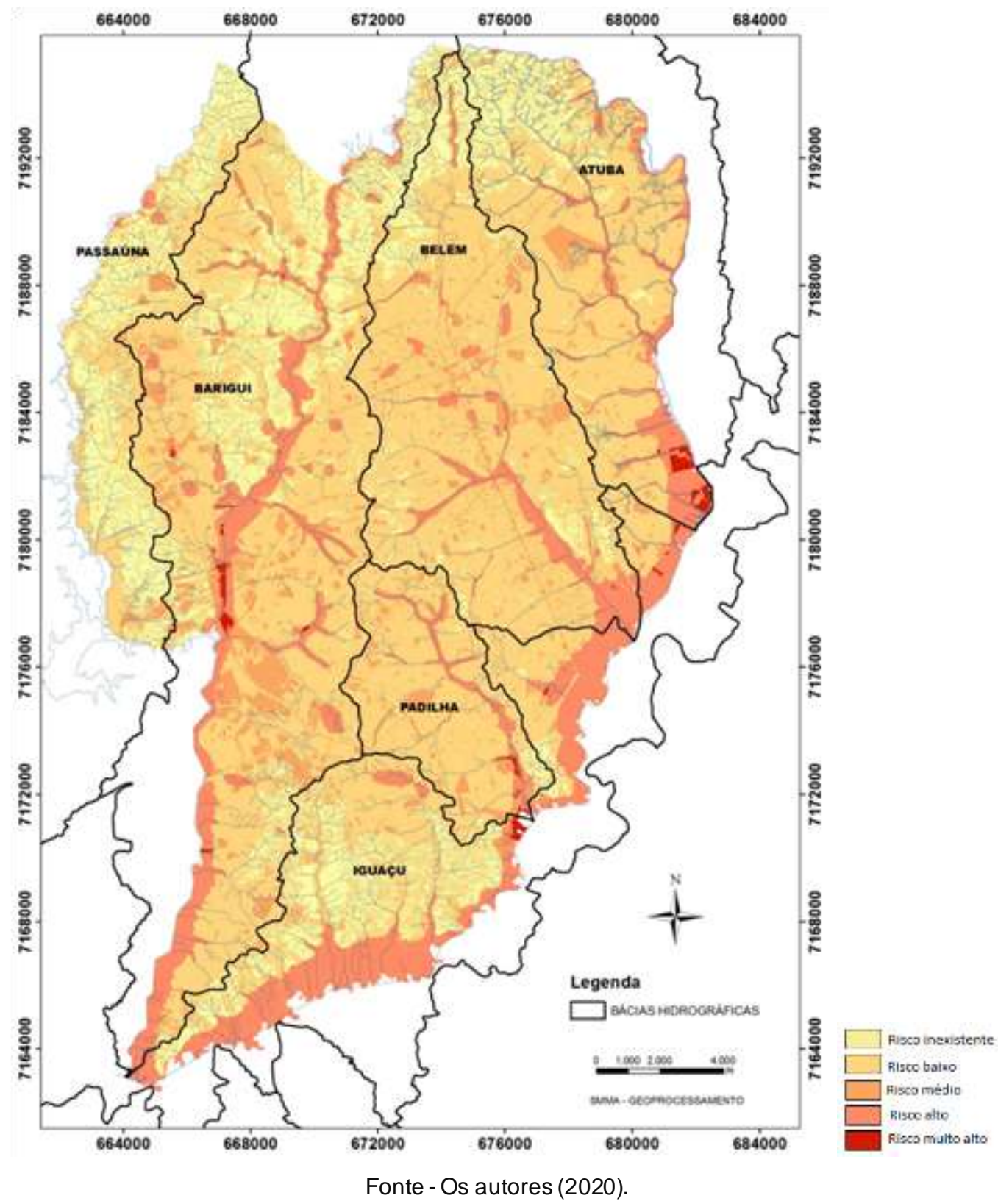

De maneira geral, o mapa obtido pode ser dividido em três partes. Uma primeira categoria englobando as classes 1 e 2 (risco inexistente e baixo), terrenos mais declivosos, compostos prioritariamente por rochas do embasamento cristalino, onde são desenvolvidas atividades de baixo potencial poluidor e se concentram populações de maior renda. Nesses locais, que correspondem a maior porção do território do município, a possibilidade de inundações é bastante reduzida. Nestas classes podem ocorrer tão somente alagamentos por interrupção da microdrenagem ou fatores que não foram alvo de levantamento por este trabalho. A categoria englobando as classes 4 e 5 , corresponde às áreas ef etivamente sujeitas a risco permanente de inundação, em caso de precipitações atmosféricas acentuadas. São áreas constituídas geolog icamente por 
planícies aluvionares, baixa declividade, onde estão instaladas habitações subnormais e populações de menor renda (FIGURA 7). Na classe 3, estão as situações de risco mediano.

Figura 7 - Áreas de risco em Curitiba.

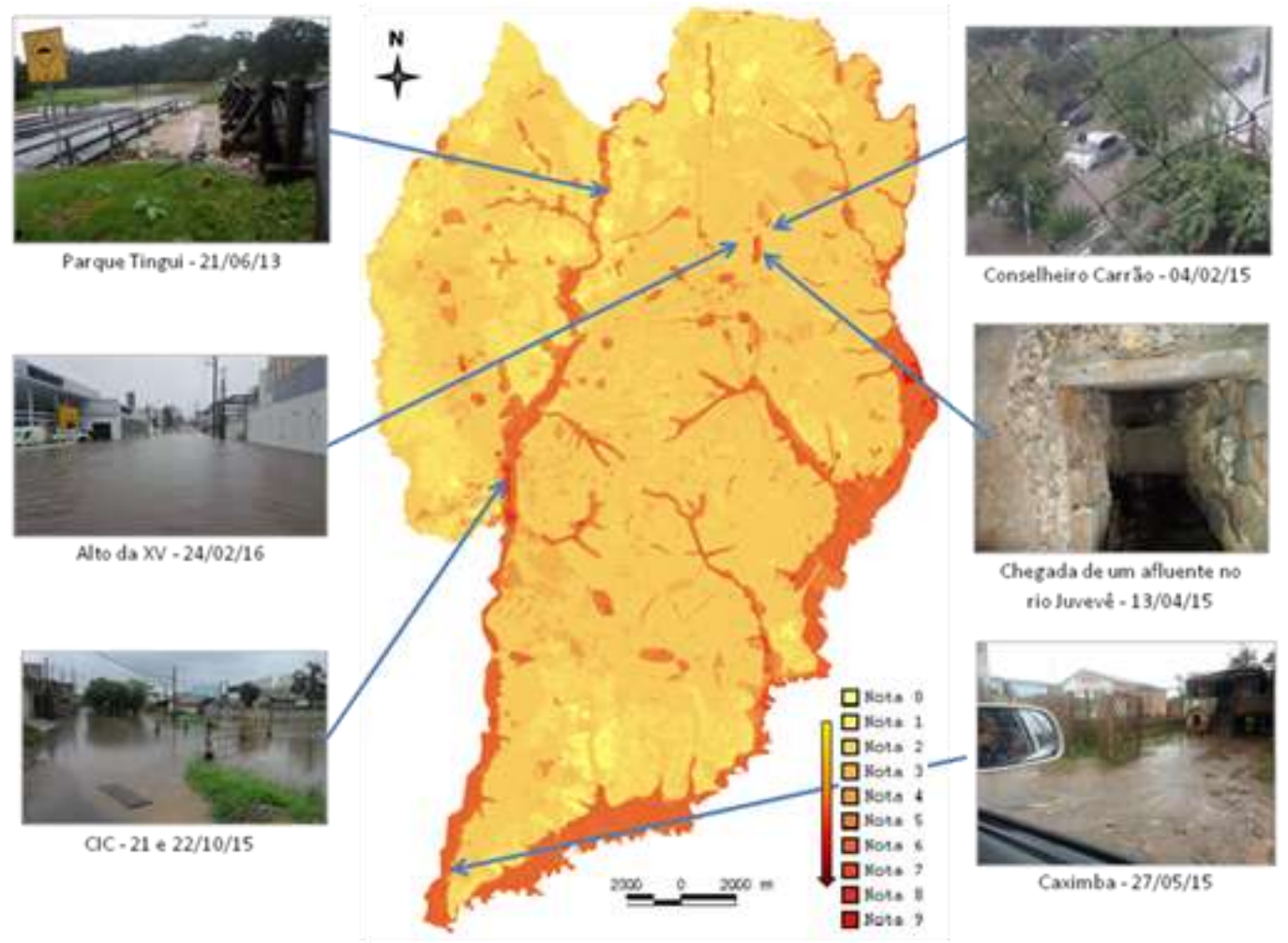

Fonte - os autores (2020).

A metodologia proposta e aplicada nesse estudo tornou possível a identificação das áreas de maior risco do município. Estas áreas, pertencentes às classes 4 e 5 , agora, estão sendo alvo de mapeamento em escala de detalhe, foif eita a fotointerpretação e será f eito mapa em escala 1:8000, de modo a complementar estudos que possam auxiliar no planejamento de obras estruturais ou intervenções junto à comunidade exposta, tais como a sua remoção, organização em núcleos de resposta a desastres ou modificação do estilo construtivo das moradias nos casos em que não a remoção não seja possível.

\section{CONCLUSÃO}

A abordagem tradicional do poder público não tem sido eficiente na prevenção, na preparação, na resposta ou até mesmo na eliminação dos episódios provocados por eventos climáticos extremos, muito pelo contrário, por vezes até agravando suas consequências. A dificuldade de combater as consequências negativas geradas pela ocorrência de inundações na cidade, intensificadas pela impermeabilização do solo e ocupação de áreas inadequadas, é exemplo do que se afirma. A "artificialização" da rede natural de drenagem (rios, lagos, várzeas, nascentes etc.), através de canalizações, retificações e confinamentos, não tem dado conta de eliminar os problemas, mas sim aumentado à frequência de eventos.

O mapeamento de risco permite que, além das ações e intervenções imediatas e mediatas em áreas mais problemáticas, se defina e priorize as demais etapas nas quais o município deverá atuar em uma gestão ambientalmente adequada ao seu meio físico, otimizando tempo e recursos e proporcionando melhor qualidade de vida a população. A ferramenta utilizada para elaboração do mapa de risco é gratuita, de fácil manuseio. Dada à eficácia que essa ferramenta apresenta, ela torna possível a qualquer município estabelecer as áreas prioritárias para atuação na redução dos riscos de desastres, devendo investir na apuração de dados confiáveis e informações de qualidade.

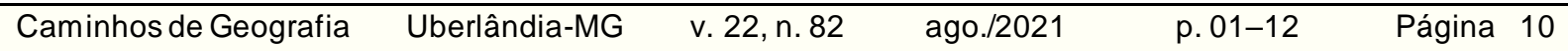




\section{REFERÊNCIAS}

BARROCA, B., BERNARDARA, P., MOUCHEL, J. M., HUBERT, G. Indicators for identification of urban flooding vulnerability. Natural Hazards and Earth System Science, v. 6, 2006, p. 553-561. https://doi.org/10.5194/nhess-6-553-2006

BIGARELLA, J. J., SALAMUNI, R. Caracteres texturais dos sedimentos da Bacia de Curitiba. Geologia. Boletim da UFPR, n. 7, 1962, p. 1-164.

BRASIL. Lei n. 12.608, de 10 de abril de 2012. 2012. Disponível em: <http://www.planalto.gov.br/ccivil_03/_Ato2011-2014/2012/Lei/L12608.htm>. Acesso em: 20/05/2020.

CANALI, N., MURATORI, A. M. Síntese da evolução geomorfológica da bacia de Sedimentação de Curitiba. In: 3‥Simpósio Regional de Geologia. Curitiba. Sociedade Brasileira de Geologia. Núcleo de São Paulo novembro, 1981, Atas, vol.2, 389p

\section{CEPDEC/PR. COORDENADORIA ESTADUAL DE PROTEÇÃO E DEFESA CIVIL DO PARANÁ.} Relatório de ocorrências. 2020.

CEPED-UFSC. CENTRO UNIVERSITÁRIO DE ESTUDOS E PESQUISAS SOBRE DESASTRES. UNIVERSIDADE FEDERAL DE SANTA CATARINA. Atlas Brasileiro de Desastres Naturais: 1991 a 2012. Centro Universitário de Estudos e Pesquisas sobre Desastres. 2. ed. Florianópolis: CEPED-UFSC, 2013. $126 \mathrm{p}$

CUNICO, C. Do risco à adaptação: a identificação da vulnerabilidade socioambiental de Curitiba - PR. 288f. Tese (Doutorado em Geografia), Universidade Federal do Paraná, Curitiba, 2013.

DESCHAMPS, M. V. Vulnerabilidade socioambiental na região metropolitana de Curitiba/PR. $192 \mathrm{f}$. Tese (Doutorado em Meio Ambiente e Desenvolvimento) - Universidade Federal do Paraná, Curitiba, 2004.

FONSECA, M. N. da.; FERENTZ, L.M.S. Percepções sobre as consequências e prejuízos de inundações: estudo aplicado em Pinhais, Paraná. Revista Brasileira de História \& Ciências Sociais - RBHCS, vol.12, n.23, 2020. https://doi.org/10.14295/rbhcs.v12i23.11135

FONSECA, M. N. da; GARCIAS, C. M. Comunicação de risco de inundação: instrumento fundamental da gestão de riscos de desastres. DRd - Desenvolvimento Regional Em Debate, vol.10, p.1139-1159, 2020. https://doi.org/10.24302/drd.v10i0.2882

GEISSLER, H.J., LOCH, R.E.N. Análise histórica das enchentes em Curitiba-PR: medidas propostas e consequências observadas. In: SIMPÓSIO BRASILEIRO DE DESASTRES NATURAIS, 1., 2004, Florianópolis. Anais... Florianópolis: GEDN/UFSC, 2004. p. 507-523. CD-ROM

HILL, A.A., CUTTER, S.L. Methods for Determining Disaster Proneness. In: CUTTER, S. L. (Ed.). American Hazardscapes: The Regionalization of Hazards and Disasters. National Academy of Sciences, Washington, D.C., 2001, p. 13-36.

IBGE. Instituto Brasileiro de Geografia e Estatística. Manual técnico de pedologia. 2. ed. Rio de Janeiro: IBGE, 2007

Sinopse do Censo Demográfico de 2010. Rio de Janeiro: IBGE, 2010

Mapas temáticos: Clima. 2018. Acesso em: Junho de 2018.

IPARDES. Instituto Paranaense de Desenvolvimento Econômico e Social. Caderno estatístico do município de Curitiba. 2018

LIMA, R. E. Uso dos solos e dos rios: conceitos básicos e aplicações para Curitiba. Curitiba: NIMAD/UFPR, 2000. 
MARANDOLA JR., E., HOGAN, D. Natural hazards: o estudo geográfico dos riscos e perigos. Ambiente e Sociedade. Campinas, ANPPAS, v. 7, n. 2, p. 95-109, jul./dez. 2004. https://doi.org/10.1590/S1414$\underline{753 \times 2004000200006}$

MENDONÇA, F., DANNI-OLIVEIRA, I. M. Climatologia: noções básicas e climas do Brasil. São Paulo: Oficina de Texto, 2007. $206 \mathrm{p}$

MENDONÇA, F.A., BUFFON, E. A. M., GOUDARD, G. L'adaptation urbaine au changement climatique global: les inondations à Curitiba et Pinhais (Brésil) In: XXVIIle Coloque de l'Association Internationale de Climatologie. Liège (SartTilman)/Belgique, p. 200-205, 2015.

MONTEIRO, C.A.F. Clima In: A Grande Região Sul. Rio de Janeiro: IBGE, Tomo 1, v. 4, p.14-166, 1968.

Clima e Excepcionalismo: conjecturas sobre o desempenho da atmosfera como fenômeno geográfico. Florianópolis: Editora da UFSC, 1991.

OLIVEIRA, M. A. Da espacialidade rural-extrativista à cidade-jardim: Curitiba (1900-73): In. MENDONÇA, F. (Org.). Cidade, ambiente e desenvolvimento: abordagem interdisciplinar de problemáticas socioambientais urbanas de Curitiba e RMC. UFPR. Curitiba. 2004. p. 71-52

ONUBR. ORGANIZAÇÃO DAS NAÇÕES UNIDAS NO BRASIL. ONU: Brasil está entre os 10 países com maior número de afetados por desastres nos últimos 20 anos. Nações Unidas no Brasil, 2015. Disponível em: <https://nacoesunidas.org/onu-brasil-esta-entre-os-10-paises-com-maior-numero-deaf etados-por-desastres-nos-ultimos-20-anos/>. Acesso em: Nov. 2018

PINHEIRO, E.G., FERENTZ, L.M.S., FONSECA, M.N. As Emergências Ambientais no Paraná e as Intersecções com o Sistema Estadual de Proteção e Defesa Civil. Redes (Santa Cruz do Sul. Online), v.24, n.2, p. 81-98, maio-agosto, 2019. https://doi.org/10.17058/redes.v24i2.12995

SALAMUNI, E., SALAMUNI, R., EBERT, H. D. Contribuição à geologia da Bacia Sedimentar de Curitiba (PR). Boletim Paranaense de Geociências, v. 47, 1999, p. 123-142.

SALAMUNI, E., EBERT, H.D., HASUI, Y. Morfotectônica da Bacia Sedimentar de Curitiba. Revista Brasileira de Geociências, v. 34, 2004, p. 469-478. https://doi.org/10.25249/0375$\underline{7536.2004344469478}$

UFRJ/LAGEOP. Universidade Federal do Rio de Janeiro. Laboratório de Geoprocessamento. Vista Saga 2007 (software). 2007. Disponível em: <http://www.viconsaga.com.br/lageop/downloads.php>. Acesso em: 20/05/2020.

UNDP - United Nations Development Program. Reducing disaster risk: a challenge for development. New York: UNDP, 2004, $130 \mathrm{p}$.

ZANELLA, M. E. Inundações Urbanas em Curitiba/PR: impactos, riscos e vulnerabilidade socioambiental no Bairro Cajuru. Tese (Doutorado). Meio Ambiente e Desenvolvimento, Universidade Federal do Paraná, Curitiba, 2006.

Recebido em:28/05/2020

Aceito para publicação em:04/05/2021 